\title{
Disclosure and Hiding Online. Pleading for Prevention of Online Violence among Teenagers
}

\author{
Maria Diaconescu ${ }^{1}$ \\ ${ }^{1}$ Babeș-Bolyai University of Cluj-Napoca, Department of Social Work, 128-13021 Decembrie 1989 Bld., 400604 Cluj-Napoca, \\ Romania
}

KEYWORDS

Online interaction

Self-disclosure

Trustworthiness

Controllability

Self-protection

Preventing online and

offline violence by

empathy and

assertiveness training
ABSTRACT

The present paper discusses disclosure, hiding and self protection in the current online interactions among teenagers. It focuses on disclosure of inner feelings and attitudes, and hiding as a form of self protection online. We explore more specific the following questions: How the feelings and attitudes are disclosed and understood online when teenagers use instant messenger; For what do teenagers choose to disclose themselves on instant messenger and control the conditions of their interactions online? The qualitative research method we used to explore the mentioned questions was the offline and online interview. Two hypotheses emerged and are presented as the results of this study. These are analysed, illustrated by teenager's responses, discussed and on hand to be verified with statistical method in further quantitative research. Reduced nonverbal cues online reduce the accuracy of empathic understanding which do not stop teenagers to disclose and develop sympathy online. Teenagers choose to disclose themselves online in order to get and/or to maintain a sense of belongingness, to get help or to exercise assertiveness and self-confidence. They learn to control the conditions of their online interactions in order to play with each other or to protect their selves from potential hurts and unwanted intrusions: they choose either to gossip, attack or to hide them online. The present study pleads for action research and building social programs in order to prevent online and offline violence.

* Contact address: mdia19@yahoo.co.uk (M. Diaconescu) 


\section{Introduction}

The researches suggest that at least $80 \%$ of the teenagers use Internet for online communication. For example: Valkenburg and Peter's (2007) research carried out in spring of 2004 shows that in Holland $88 \%$ of the respondent teenagers aged 10-16 years use the Internet for IM or chat primarily to maintain their existing network of friends. Pew Internet Project, referenced by Goodstein (2007), carried out in winter of 2005 shows that $83 \%$ out of five thousand U.S. and Canadian teenagers use IM.

The statistical data of our research carried out in autumn of 2007 in Romania, Cluj-Napoca (Barbovschi and Diaconescu 2008)1, show that 90\% $(\mathrm{N}=1550)$ of preadolescents and adolescents (teenagers) use IM: $67 \%$ of them talk everyday or almost everyday on IM with their friends; $47 \%$ with their colleagues; $25 \%$ with people from Cluj they had met for the first time on the Internet, and met later also face to face; $20 \%$ with people from Cluj they have never met face to face, and $17 \%$ with people from Romania they have never met face to face; $31 \%$ with people from Romania living abroad they have met face to face before talking on IM; $15 \%$ with people living abroad they have met face to face.

Our data show moderate signs of concern when it comes to selfprotection online. Both boys and girls are aware of the dangers of online publicly available personal data. From the $70 \%(\mathrm{~N}=1200)$ of preadolescents and adolescents who have a personal profile (like Hi5 or Facebook), 95\% have not made public neither their phone number nor their home address $(94 \%)$, nor their full name (78.4\%). With the exception of full name, which boys tend to disclose more often, there are no significant differences between boys and girls. $8 \%$ of the boys and $3 \%$ of the girls search online often and very often persons to date (on specific dating sites), and more than $90 \%$ do not send (or send very rarely) emails in order to meet strangers from Internet.

Email and chat rooms are very seldom used by teenagers. More than $60 \%$ of our respondent teenagers send emails just 2 or 3 times in a month in

\footnotetext{
1 In October and November 2007, 1806 self-report questionnaires were administrated in secondary and high schools in Cluj-Napoca among teenagers between 12-18 years. ClujNapoca is a town from Transylvania, North West part of Romania.
} 
order to communicate with their friends, class mates or relatives. $76 \%$ of our respondent teenagers do not use chat room at all, and $9 \%$ of them use it often or very often.

Furthermore, the above mentioned data generated the following questions:

1. Which is the quality of the textual talk on IM with their friends, colleagues, relatives and online friends? This question aimed at the feelings and attitudes experienced in their online interactions, disclosure and self-protection in their online experiences with friends and strangers, how they express and understand online instant messages comparing with face to face messages, a.s.o.

2. Which is the quality of their communication on Hi5, Facebook, MySpace? This question aimed at the experience they lived with their and others' personal profile, disclosure of private information, hiding, adding friends on Hi5, meanings of the added 'online friends', a.s.o.

3. What do teenagers recommend to the children as future internet users, to their parents and teachers in order to strengthen the positive effects of the internet and make the online space a safer space for them?

4. How the teachers perceive the internet use among children and teenagers?

The aims of the mentioned questions are to deepen the understanding of online experiences and meanings from the view point of the interviewed preadolescents and adolescents: the benefits and potential risks of IM and Hi5 use among them; the online development of online and offline human resources to meet their needs; the strategies to make the online space a safer space for them.

The present paper presents a part of the entire qualitative research and focuses on online disclosure of inner feelings and attitudes, and on anonymity - hiding as a form of self protection online. Two hypotheses emerged and are presented as the results of this study. 


\section{Theoretical framework}

Peter and Valkenburg's (2006) analysis focuses on how adolescents perceive the controllability, reciprocity, breadth and depth of internet communication in comparison with face-to-face communication. In their study, controllability means that the adolescents can easily control if, when, how, how much and what they communicate to others on the internet. Reciprocity means that the adolescents feel that they and others are more responsive in Internet communication than in face-to-face communication. Peter and Valkenburg (2006) have found that younger, socially anxious and lonely adolescents more strongly value the controllability of internet communication and perceive it as broader, deeper and more reciprocal than older non-socially anxious and non-lonely adolescent respondents. Boys perceive internet communication as more reciprocal than girls do. The greater the adolescents' need for affiliation, the more often they regard internet communication as deeper than face-to-face.

Schouten, Valkenburg and Peter's study (2007) tests and confirm the hyperpersonal communication theory which assumes that reduced nonverbal cues and controllability of IM facilitates disinhibition which in turn increase self-disclosure. Furthermore, the feelings of disinhibition are stimulated by teenagers' perceived relevance of controllability and reduced nonverbal cues (visual and auditory) and social context cues (as social status). Teenagers with high private self-consciousness judge controllability of IM more relevant because IM gives them more time and opportunity to reflect upon their own inner feelings, meanings and attitudes and how to express them online. Private self-consciousness refers to the inner aspects of self and to the tendency to focus attention on more private and covert aspects of oneself (according to Franzoi \& Davis 1985 apud. Schouten et al. 2007). Teenagers with high public self-consciousness judge controllability of IM more relevant because IM allows them more time and opportunity to optimize their selfpresentation. Public self-consciousness is the awareness of how one appears in the eyes of others (according to Fenigstein et al. 1975 apud. Schouten et al. 2007). The study shows also that, on average, teenagers tend to self-disclose less online than they do offline in same-sex interactions. This also held for cross-sex self-disclosure, where teenagers also disclose slightly more offline. 
However, the authors (Schouten et al. 2007) suggest that for many teenagers, IM may be particularly helpful in their cross-sex self-disclosure. In cross-sex interactions, $32 \%$ of adolescents self-disclosed more online than offline. In same-sex interactions, $22 \%$ of adolescents self-disclosed more online than offline. In their cross-sex self-disclosure, IM seems to be even more helpful for boys (35\%) than for girls (28\%), as their results and authors suggests. Because boys generally may have more difficulty self-disclosing than girls, the boys may especially benefit from IM's controllability and reduced nonverbal cues to stimulate their self-disclosure.

The feelings and attitudes experienced by the person (the person who disclose his/ her feelings) here and now are mostly disclosed nonverbally in face to face context, and represent the core aspect in the effort of the empathic understanding (Egan 1994) the other partner of the dialogue strives to get (the person who makes the effort of empathic understanding). The empathic attitude works like a mirror - even if an imperfect mirror: 'You feel..., because the fact/ you think/ believe that...' - which reflects the honest acceptance and understanding of the other in terms of his or her feelings, needs and meanings (person who disclose his/ her feelings). The key of empathy, according to Rogers (1989) is:

'to be present in relationship here and now. There are different levels of empathic understanding, positive regard/ unconditional acceptance, and authenticity. Only the presence has the quality of the "to be or not to be": to be or not to be in psychological contact, in relation.'

Empathy, as conceived by Rogers (1989), means that I feel the inner world of the other with all his/her personal feelings and meanings 'as if' these were my own world of feelings and meanings without losing the quality of the 'as if'. Empathy means that I feel the anger, fear or confusion of the other 'as if' these were my own feelings without allowing my own anger, fear or confusion to interfere. However, if I 'put myself into somebody else's shoes' in order to see how I do in fact feel 'in another's shoes', it means that I attribute my own feelings and meanings to the other. This is not empathy; this is projection. In its conscious variant this projection is expressed in the first person as 'I feel exactly the same way...' or 'For me it means...'. This kind of conscious projection has the potential to generate sympathy and solidarity because I assume responsibility for my own feelings and meanings 
without projecting or inserting them unconsciously into the 'another's shoes' (Diaconescu 2007). To allow myself to walk in 'the other's shoes' or to fall off my own chair when the other is fidgeting or is moving erratically on his/ her own chair, suggests that I have lost the quality of 'as if':

'If you believe that you have to have empathy that means that you have to have the same feelings that your client does in order to function well as a therapist' (Bandler and Grinder 1979).

This is not empathy; this is empathic identification.

The more honest the immediate, or the here and now feedback is from the person who relates the experience (or the more authentic, in terms of existentialism) the better is the chance of the empathic message approximating the intended message. Without immediate verification of the understanding gained, every act of empathy or intuition risks becoming pure fantasy, projection or barriers in communication. The only way in which we can verify the empathic understanding that we have gained is by verbalising this understanding, here and now, in relationship and dialogue with the other who gives us the experience with which we empathise: 'The fact is.../You believe/think that..., and this makes you feel... Do I understand correctly?'. In this way we allow the other to immediately point out to us the errors of understanding that we inevitably commit. It is no accident that verbalising our understanding is so important in Carl Rogers' psychotherapy. With this attribute of verbalizing we remove ourselves from the comfortable episteme of knowledge, and we enter into the fluid and uncomfortable episteme of communication (Diaconescu 2008).

The phenomenon which is known as authenticity in existentialism, in Carl Rogers' branch of psychotherapy it is known as congruence, which means the overlapping of analogue and digital messages. Putting it in a simpler way, what we think coincides with what we say and what we do in relation to a given situation. For instance, when facial expressions or tones of voice are inconsistent with spoken words, the facial expression or tone of voice is that which is given the greatest credibility. This kind of incongruence between statement and nonverbal behaviour is illustrated by Ivey (1994) in the following two examples: 1. 'That question doesn't bother me', said with a flushed face and closed fists, or 2. 'I really love my brother', said in a quiet tone with averted eyes. 
In the context of written, textual online interaction, the congruencies and discrepancies between two textual statements are obvious. On the other hand, in the context of face-to-face conversations they can be heard. For instance, the following discrepancy between statements: 'My son is perfect, but he just doesn't respect me', can be written online, or uttered in a face-toface interaction or in a phone conversation. Other congruencies and discrepancies, as described by Ivey (1994), are entirely invisible online. For example, the congruencies and dissimilarities between statements and nonverbal behaviours, between nonverbal messages, between what one says and one does are invisible online. This phenomenon of limited physical sensory information is called online disembodiment. If our face to face communications consist in 7\% words, the rest of $93 \%$ means a decline of nonverbal cues in our online communication ${ }^{2}$. Because of the decreased nonverbal cues, says Turkle (1995) apud Kang (2007), in online interaction the partners are likely to experience more intense and intimate self-disclosure and less social responsibility towards the others than in face-to-face communication.

The studies of Feng, Lazar and Preece (2004) explore the influence of empathy on interpersonal trust in the textual online communication environment. The authors consider that empathy results from the observation of nonverbal messages in face to face communication. Although these messages are missing in online text communication, people develop a certain degree of empathy and start trusting one another within certain contexts. The studies mentioned by the above authors show that relationships build up and, based on previous face to face encounters, as well as on previous face to face interaction using audio or video or both, encourage and support, to a much higher degree, reciprocal trust and cooperation in online text communication than does online text interaction alone. I noticed the so called empathic messages, like 'I feel the same as you $\mathrm{do}^{\prime}$, in fact, indicate sympathy, not empathy. My view is based on the definition of empathy in psychotherapy and counselling worked out by

\footnotetext{
2 Egan (1994) mentions a study of Mehrabian who initiated his research with the question: what indexes are used by humanity in order to identify sympathy or antipathy towards others? Mehrabian found that only $7 \%$ of our messages are verbal or digital. He further discovered that sound indexes would contribute at a rate of $38 \%$, while facial expressions contribute at a rate of $55 \%$.
} 
Rogers (1989), Egan (1994) and Ivey (1994). The implicit definition of empathy under laying the study of Feng et al (2004) seems to me as inadequate. At any rate, the mentioned study admits the importance of nonverbal signs in empathy, even if the definition of empathy points to sympathy. In the conclusion to the same study I read that so called empathy, in fact sympathy - as I have already pointed out - encourages reciprocal understanding and trust in the online text communication environment. The implied rule of sameness which is given by the common needs, aspirations, feelings, features and actions of teenagers, and on which their reciprocal sympathy is relying: 'birds of a feather flock together' becomes for teenagers a very important rule of affiliation and their most important source of mutual esteem and respect. Finally, it becomes obvious that online trust results from offline and online reciprocal disclosure, acceptance and understanding which in turn strengthen sympathy and trust.

Nissenbaum (2001 apud Weckert 2005) argues that the conditions for the creation and maintenance of trust offline are not present online. One of these is missing identity; online is not clear whom we are communicating with, so it is difficult to know whether it is someone trustworthy. And because they are anonymous, more or less, there is less reason to believe that they will act responsibly. In addition, it is often difficult to know whether we are communicating with the same person over time. The second problem, according to Nissenbaum (2001 apud Weckert 2005), is missing personal characteristics; many of the cues that we use to assess trustworthiness are missing, the communication channels are very narrow, no body language is conveyed, so reliance is purely on the verbal, and that itself is limited to the written word. According to Weckert (2005), online we have an amount of control over how we present ourselves to others that is not possible in the offline world. Therefore, nobody can get to know our characters in the way that is common in friendship. I know my friends' strengths and weaknesses, and they know mine, says Weckert (2005), but we are friends nonetheless. Although this is an argument about friendship, it is relevant also to trust. If we have a high level of control over how we present ourselves to others, it is highly likely that the presentation will contain more of our favourable attributes than the less favourable ones. The possibility of deception is also 
increased, so not only is the possibility of true friendship lessened, says Weckert (2005), but so is the possibility of trust.

\section{Method}

Research design and measures

The central questions of this study emerged from a phenomenological perspective and focus on how teenagers describe their experiences of online interaction, how they perceive them, judge and feel them. The desired result of the present applied research is to contribute to theories that can be used to formulate problem-solving programs and social interventions. Consequently, we adopted a qualitative approach, with in-depth interview as the main method of data collection.

The research method we used to explore the mentioned questions in the Introduction section was the offline and online individual in-depth interview with teenagers and focus group with teenagers and teachers. A lot of qualitative interviewing research strategies are current strategies in Psychotherapy and Counseling: successive open questions, active listening, reflecting back the understood meanings and feelings etc. The following questions are some example of the questions used in the in-depth interviews: Describe what you like when you are online with your friends, colleagues or relative; Describe what upsets you more online; But those whom you interact? (When they lose patience/get upset with you?); what do you think, young people (girls/boys?) do more often gossip online, or offline? What differences do you perceive online/offline and how do you explain these differences? (Discreetly, without touch of blame) But do you gossip more often online or offline? How do you explain the differences? Online, do you fight? (Criticism, advice friendly tone of care, violent exchanges of messages, attacks or blackmail, insults, etc.). If you are attacked online, how do you feel and answer to the attack? Online do you express what you feel and think easier than face to face? Under what circumstances/ What differences online/offline do you perceive, how do you explain the differences? Online messages do you understand easier, with more accuracy than if the same messages would be expressed orally/offline?, etc. 


\section{Participants}

Teenagers between 12-18 years old who took part in the previous survey were asked to give their email address if they were agreeing to take part in the interviews. We received 500 email addresses in the last page of the 1806 self-report questionnaires. In our initial attempts to contact teens for interviews, we received almost no answers by email. Therefore, we had no choice but to contact them by instant messenger. Finally, we get 18 individual interviews: 10 face to face interviews - offline, 8 textual interviews on Yahoo Messenger - online, 2 face to face focus groups with teenagers and 2 with teachers. All teenagers had have access to the Internet from their home and personal computer. Three boys (9-18 years old) and seven girls (13-18 years) took part in the offline interviews. From the eight online interviews, four of them are invalid because the very low motivation and engagement in the interview. Two boys (13 and 16 years old) and two girls (16 and 18 years) took part in the four valid online interviews. Twelve teenagers (10 girls and 2 boys) took part in the two focus groups (one boy in each group). Eight teachers (6 women and 2 men) took part in the two focus groups (one man in each group).

\section{Procedures}

Face to face offline interviews lasted between 30 minutes and 2 hours. Textual online interviews lasted between 15 minutes and 3 hours and were carried out in condition of faceless and soundless anonymity that is we had not met face to face with the interviewees before or did not met them after the online interviews. Focus groups lasted around 2 hours each of them.

\section{Data analysis}

Interview responses were analysed and the similarities and differences of the responses were grouped according to the following themes: 1. positive effects, and 2. risks of internet use among teenagers as the teenagers perceive them, 3. teenager's recommendations for a safer online space for the future generations, and 4 . the teachers' perceptions regarding the positive effects and risks of internet use among children and teenagers. For the present paper I selected the responses that illustrate better the generated hypothesis. 


\section{Results: theoretical concepts \& hypothesis illustrated by teenagers' responses}

Disclosure (disclosure of personal data, expressing/ asserting own feelings, attitudes, needs, preferences, asking help):

Girl, 18 years old (offline): I have an online girl friend from abroad. I have never met her face to face. She started to talk first about her personal things. The disclosure, the exchange of the information, became reciprocal. I trust her because I see that we have a lot of common interests (disclosure, sympathy).

Girl, 18 years old (online): It's impossible to notice certain details online, it's different when a person is standing in front of you and you witness the person's happiness and voice congratulations... it's easier that way to notice when someone is honest 3 (need to feel the aliveness and to check the authenticity).

Girl, 17 years old (online): There are no words to express exactly what I feel, anyway, when meeting someone face to face you can show things without saying them.

Boy, 17 years old (offline): When they are hidding their feelings online with emoticons, I can quess them. Their answers are very slow or they do not reply anymore. With a friend I can usually check. A close person lets me know after some questions what is happening (sensing the authenticity and disclosure).

Hypothesis no. 1: Reduced nonverbal cues online reduce the accuracy of empathic understanding which do not stop teenagers to disclose and develop sympathy online. Disclosure is an important condition to develop friendships and romances, affinities and a sense of belongingness which in turn stimulate more disclosure. Sympathy online and/or offline, not empathy online, encourages online trust which results from offline and online reciprocal disclosure, acceptance and understanding in the online text communication environment among teenagers.

If our face to face communication consists in 7\% words, the rest of 93 $\%$ means a decline of nonverbal cues in online communication. This is online

\footnotetext{
${ }^{3}$ Need of certitude online, is blocked; the congruence between the verbal and nonverbal messages is impossible to check immediately online because the nonverbal aspects of the messages are entirely missing, therefore their authenticity is sooner or later questionable.
} 
disembodiment. Face to face, feelings and attitudes are disclosed nonverbally. Empathic understanding of them relates to the nonverbal cues. This kind of understanding requires feeling the aliveness and authenticity of the disclosed messages. It results the need to see and hear how the messages relate to each other, to sense their congruency and check the understanding.

Anonymity (hiding personal data, own gender, age, occupation, feelings and attitudes, or interests, in order to take advantages/ revenge, benefit, for self-protection):

Girl, 18 years old (online): Time to time I have fun cheating the strangers for 2-3 days. I change my age and sex. The other feels later or sooner or finds out somehow that I am not so old and I feel uncomfortable and vanish from YM. I am wiser in cheating than others and can protect myself from those who want money, sex or to sell me drugs (selfprotection).

Boy, 17 years old (offline): I talked with her on YM and did not tell her that I am me, her classmate. I wanted to cheat her, to take revenge. I was wrongly judging her; all of us were judging her. I was not proud of me at all and stopped it. Now, we are good friends and understand very well each other (revenge).

Girl, 18 years old (online): It's easier when you write all those things, you can mask a lot of things 4 when chatting:)... you can use emoticons like ":))" and you can be ironical or cool, at least you can leave the impressions that you're like that... indifferent:)... :P ...even when you're very angry... especially then, you say silly things when you speak but you don't write them...(protection).

Boy, 17 years old (offline): Face to face you can not hide and protect from a humiliating look or voice. Online everybody feel powerful. You can prepare your messages; you do not feel intimidated by my look or voice. (hiding, control, self-protection).

Hypothesis no.2: Controllability of IM possible facilitates the development of assertiveness and self-confidence (not just attacks/ gossips) online and offline. IM gives more time and opportunity to reflect upon their own inner feelings,

\footnotetext{
${ }^{4}$ Need of self esteem, to avoid showing vulnerable feelings, to keep control on feelings. Being in the others' presence, it is much more difficult to keep the feelings of one's own power, control and independence. On the other side, when the context or relationship is safe enough to show authentic feelings online, the words are not enough to describe and express the feelings and their meanings online, therefore the risk of misunderstandings is much greater, and those misunderstandings might easily show up online.
} 
meanings and attitudes, how to express them online or how to optimize their self-presentation. In this way, teenagers also learn to hide themselves in order to protect their self from unwanted and undesirable effects of barriers which block the communication in face to face context (criticism, attacks, evaluations, judgments of others).

\section{Discussion, conclusions and further research}

The implied rule of sameness becomes for teenagers a very important rule of affiliation and their most important source of mutual esteem and respect. This rule of affiliation is given by the common needs, aspirations, feelings, features and actions of teenagers, on which their reciprocal sympathy is relying. Sympathy encourages online trust which results from offline and online reciprocal disclosure, acceptance and understanding which in turn strengthen sympathy and trust. Hypothesis no. 1 emerged: Reduced nonverbal cues online reduce the accuracy of online empathic understanding which do not stop teenagers to disclose and develop sympathy online. Verifying this hypothesis with statistical methods would clarify the limits of online empathy among teenagers and remove also the confusion between sympathy - empathy projections.

In addition, hypothesis no.1 argues for action research, a kind of research that is preceded by action and suggests the development of social programs for prevention of online and offline violence that is empathy training using online and offline video and audio means, both among children and adolescents, also among parents and teachers.

Teenagers learn to control the conditions of their online interactions and they love to hide themselves online in order to play with each other and to protect their self. They protect themselves from unwanted and undesirable effects of barriers and abuses which block the face to face communication: criticism, judgements, evaluations, attacks, and exploitation of others. This could be a serious sign on what's up offline, the social problems which remain invisible and silent offline and become more and more visible online. Among the partners of online conversation the need to be respected by the other and to accept his/ her otherness emerge more easily. They might feel belongingness and acceptance of the other to be 
much easier because online they feel safe enough to express negative feelings and crazy ideas without being afraid of possible criticism or emotional abuse. Hypothesis no. 2 emerged: Controllability of IM possible facilitates the development of assertiveness and self-confidence (not just attacks/ gossips) online and offline, which also can be verified with statistical method.

The interview data confirm the hypothesis no. 2 only in part, for the online communication, not for offline communication. A single interview suggests that the hypothesis could be possible: boy, 17 years, in the offline interview:

I talked with her on YM and did not tell her that I am me, her classmate. I wanted to cheat her, to take revenge. I was wrongly judging her; all of us were judging her. I was not proud of me at all and stopped it. Now, we are good friends and understand very well each other.

The other responses reflect only the ability to control, hide and protect online. Even if a relevant aspect, the fact that the adolescents can easily control if, when, how, how much and what they communicate to others on the internet, that is controllability of IM, I think it is not the only relevant one, for sure not enough for the development of assertiveness and selfconfidence online and offline.

Online communication which gives room for reflection upon own inner feelings, meanings, and attitudes, and offline empathic communication which gives room for interpersonal trust facilitates the assertive communication that consists of expressing honestly personal needs, feelings, boundaries and ideas in a safe manner, in a way that will not escalate into aggression. If the actions of others threaten one's needs, feelings, ideas or boundaries, one communicates this in an assertive manner aiming to prevent violent communication: 1. aggressive communication (criticism, attacks, judgments of others, lies, etc.) or 2. passive communication (victims who passively permit others to violate their boundaries, and may come back and attack with a sense of impunity or righteous indignation at a later time). Assertive communication contributes to maintaining or increasing selfesteem and self-confidence which consists of trust, faith in one's personal judgments, ability, power, etc. when not manifested excessively as vanity or arrogance. 
Hypothesis no. 2 also argues for action research to be preceded by social programs that aim to prevent online and offline violence and victimization by assertiveness training using also online and offline video and audio means, both among children and adolescents, also among parents and teachers.

Teenagers' competence in protecting themselves of violence online seems highly developed and one could argument that teenagers do not necessarily need professional training for empathic and assertiveness training. As we have already seen, this so-called competence, aggressive or passive communication, can easily escalate into emotional violence.

Life-alienating communication, says Rosenberg (2003) traps us in a world of ideas about rightness and wrongness - a world of judgments. When we speak a language rich with words that classify and dichotomize people and their actions, we judge others preoccupying ourselves with who's good, bad, normal, abnormal, irresponsible, smart, etc. The Sufi poet Rumi, referenced by Rosenberg (2003), once wrote 'Out beyond ideas of wrongdoing and right doing, there is a field. I'll meet you there'. Teens are searching this filed also online.

\section{Acknowledgements}

This article is a result of the research project 'Risk and Effects of Internet Use among Children and Adolescents; the Perspective of Evolution towards the Knowledge Society' financed by the Romanian Ministry of Education, type A CNCSIS grant scheme (no. 1494/2007), research team coordinated by M. Roth, M. Diaconescu, M. Barbovschi. The research team consists of faculty members and graduate students from the Faculty of Sociology and Social Work of the Babeș-Bolyai University in Cluj-Napoca, Romania, as following: project director, Prof. Maria Roth and members of the research team - Senior Lecturer Cristina Baciu, Senior Lecturer Bela Szabo, Senior Lecturer Imola Antal, Teaching Assistant Maria Diaconescu, doctoral students Mihai Bogdan Iovu, Diana Damean and Monica Barbovschi. 


\section{References:}

Bandler, Richard and John Grinder. 1979. Frogs into PRINCES - Neuro Linguistic Programming. Moab: Real People Press.

Barbovschi, Monica and Maria Diaconescu (eds.). 2008. Teenagers' Actions and Interactions Online in Central and Eastern Europe. Potential and Empowerment, Risks and Victimization. Cluj Napoca: Cluj University Press.

Diaconescu Maria. 2008. The Concept of Empathy in Philosophy and Psychotherapy. Studia Universitatis Babeș-Bolyai Philosophia LIII (1-2): 105-115.

Diaconescu, Maria. 2008. Face to Face \& without Face and Sound: Offline \& Online Interaction. In Teenagers' Actions and Interactions Online in Central and Eastern Europe. Potential and Empowerment, Risks and Victimization, eds. Monica Barbovschi and Maria Diaconescu, 83-100. Cluj Napoca: Cluj University Press.

Diaconescu, Maria, Monica Barbovschi and Cristina Baciu. 2008. Beneficii şi riscuri ale utilizării internetului în rândul copiilor şi adolescenților/ Benefits and Risks in using Internet among children and teenagers. Cluj Napoca: Cluj University Press.

Egan, Gerard. 1994 [1974]. The skilled helper. A problem-management approach to helping. Pacific Grove: Brooks/Cole Pub. Co.

Feng, Jinjuan, Jonathan Lazar and Jenny Preece. 2004. Empathy and online interpersonal trust: A fragile relationship. Behaviour and Information Technology 23 (2): 97-106.

Goodstein, Anastasia. 2007. Totally wired. What teens and tweens are really doing online. New-York: St. Martin's Griffin.

Ivey, E. Allen. 1994. Intentional Interviewing and counselling. Pacific Grove: Brooks/Cole Pub. Co.

Kang, Seok. 2007. Disembodiment in Online Social Interaction: Impact of Online Chat on Social Support and Psychosocial Well-Being. CyberPsychology E Behavior 10 (3): 475-477.

Rogers, Carl. 1989. The Necessary and Sufficient Conditions of Therapeutic Personality Change. In The Carl Rogers Reader, eds. Howard Kirschenbaum and Valerie Land Henderson, 219-235. Boston: Houghton Mifflin Company.

Krueger, Richard A. and Mary Ann Casey. 2005. Metoda focus grup. Ghid practic pentru cercetarea aplicată. Iași: Polirom.

Peter, Jochen and Patti M. Valkenburg. 2006. Research Note: Individual Differences in Perceptions of Internet Communication. European Journal of Communication 21 (2): 213-226. 
Rosenberg, Marshall. 2003. Nonviolent Communication. A language of life. Encinitas: PuddleDancer Press.

Schouten, Alexander P., Patti M. Valkenburg and Jochen Peter. 2007. Precursors and Underlying Processes of Adolescents' Online SelfDisclosure: Developing and Testing "Internet-Attribute-Perception" Model. Media Psychology 10 (2): 292-315.

Valkenburg, Patti M. and Peter Jochen. 2007. Preadolescents' and adolescents online communication and their closeness to friends. Developmental Psychology 43 (2): 267-277.

Weckert, John. 2005. Trust in Cyberspace. In The Impact of the Internet on Our Moral Lives, ed. Robert J. Cavalier, 95-117. New York: State University of New York Press. 